
\title{
25 Research Suare \\ Evaluation of Smart After-Care Program for Patients With Lung Cancer
}

\author{
Hee Chul Yang ( $\nabla$ yang@ncc.re.kr) \\ Seung Hyun Chung \\ NCC: National Cancer Center \\ Ji Sung Yoo \\ National Cancer Center \\ Boram Park \\ National Cancer Center \\ Jin Ho Choi \\ National Cancer Center \\ Moon Soo Kim \\ National Cancer Center \\ Jong Mog Lee \\ National Cancer Center
}

National Cancer Center https://orcid.org/0000-0003-2605-5985

\section{Research Article}

Keywords: Smartphone, telemedicine, health care, rehabilitation, Application

Posted Date: October 19th, 2021

DOI: https://doi.org/10.21203/rs.3.rs-825440/v1

License: (c) (i) This work is licensed under a Creative Commons Attribution 4.0 International License.

Read Full License 


\section{Abstract}

\section{Introduction:}

The efficacy of telemedicine in cancer survivors is uncertain. The Smart After-care Program (SAP), which is an interactive, smartphone-based remote health monitoring system, was developed to help individual patients manage their health after leaving the hospital. This study aims to evaluate the efficacy of our remote health care program for lung cancer patients.

\section{Methods}

We enrolled 50 lung cancer patients. Self-monitoring devices were supplied to all patients, who were instructed to enter their daily vital signs and subjective symptoms to the Smart After-care app. The app also provided information about rehabilitation exercises and a healthy diet for lung cancer patients. All patients received telephone health counseling once a week and visited an outpatient clinic on the 6th and 12th week to assess satisfaction with the SAP and changes in quality of life and physical performance.

\section{Results}

Overall satisfaction with the SAP was very high (very good, 61.9\%; good, 26.2\%). In the multivariate analysis for factors affecting satisfaction, the distance between the patient's residence and the hospital was the only independent factor $(p=0.013)$. Quality of life was improved in all functional scales $(p<$ $0.05)$. Muscle strength was significantly improved in the lower limbs $(p=0.012)$. Two-minute walk distance was also significantly improved $(p=0.028)$.

\section{Conclusion}

This study demonstrated that the SAP was acceptable among and supportive of patients with reduced pulmonary function after lung cancer treatment. The study proved that the SAP was more useful for patients living far away from a hospital.

\section{Introduction}

Information and communication technology (ICT) using wireless internet and smartphone has rapidly changed how we communicate with each other. Past geographical barriers are becoming less important [1]. Recently, combinations of this ICT and biosensors have been under active discussion and new changes have been made in the healthcare industry reflecting these innovations [2-4]. Also, much medical information has become easily accessible to the general population on the internet, and as education levels rise, interest in health and quality of life (QOL) has increased. Influenced by these changes, biological monitoring using personal devices is becoming common [5]. However, many 
physicians have been hesitant to introduce remote vital sign monitoring devices into real clinical situations due to unresolved concerns [6]. First, while they may provide higher convenience, there are legal issues related to responsibility for medical care that may occur in the absence of direct physical examination. Another problem is that scientific evidence is not enough to prove if the efficacy of remote monitoring system is as expected. These concerns are more worrisome in patients with serious conditions such as cancer.

The Smart After-care Program (SAP) is a smartphone-based remote monitoring healthcare system to help individual patients manage their own health after discharge from a hospital. Initially, similar programs have been shown to be effective in patients with chronic benign diseases such as diabetes, hypertension, and arrhythmia [7-11]. Lung cancer is the leading cause of cancer death in the world. In addition, lung cancer necessarily causes the deterioration of respiratory function [12]. Thus, lung cancer survivors more worried about their health condition than patients with other cancers. Providing these patients with home monitoring of health may help to motivate them to adhere with respiratory rehabilitation by allowing them to directly recognize quantified improvements in function and may also help in early detection of deterioration in physical condition.

The primary purpose of this study was to investigate the satisfaction level with the SAP in lung cancer patients and to identify factors affecting satisfaction. The secondary purpose was to determine whether this program helped to improve QOL, cardiorespiratory endurance, and muscle strength.

\section{Methods}

The center for lung cancer, the rehabilitation center, and the Green Cross Call Center worked closely together for this study. This study was conducted in lung cancer patients who were receiving outpatient chemotherapy or making regular outpatient visits after lung resection surgery. Enrollment commenced in August 2015 and a total of 50 patients were recruited from a single institution over 3 months (Figure 1). Subjects who owned an Android smartphone (4.3 version or later) were eligible to participate if they: (1) were over 18 and under 85 years old; (2) gave consent to participate in the study (3) had relatively stable co-morbid conditions; and (4) were willing to follow the protocol of the study. Subjects were excluded if: (1) giving feedback via a smartphone was deemed to be difficult for them, (2) they had a history of any other serious illness besides lung cancer, or (3) they had difficulties in performing rehabilitation exercises.

In total, 50 patients were enrolled. Among them, 46 were undergoing outpatient observation after lung resection surgery for lung cancer, while the remaining 4 patients were undergoing chemotherapy \pm radiation treatment without surgical treatment for advanced lung cancer. The average age was $58.3 \pm 11.7$ years, with 28 males (22 females) and the average body mass index (BMI) was $23.4 \pm 2.8 \mathrm{~kg} / \mathrm{m}^{2}$. There were 27 patients with stage I, 6 with stage $\otimes, 12$ with stage $\varangle$, and 5 with Stage $\otimes$ lung cancer. Of the 46 patients who underwent surgery, 35 underwent lobectomy, 8 underwent wedge resection, 2 underwent segmentectomy, 1 underwent pneumonectomy (Table 1). As for time between surgery and study 
enrollment, 20 patients were more than 1 year after surgery, 6 patients were more than 2 months and less than 1 year after surgery, and 12 patients were less than 2 months after surgery (Figure 2). During the study, $8(16 \%)$ of the 50 patients dropped out. Among them were 5 patients (10\%) who complained of the burden from taking measurements using the devices and inputting them into the app, 2 patients (4\%) who were forced to stop due to cancer progression, and 1 patient $(2 \%)$ who did not feel the need for the program. As a result, the data analysis was conducted on the remaining 42 patients.

All the remaining subjects visited the hospital three times over a three-month period, at six-week intervals. At the time of initial registration, patients completed a baseline QOL survey (EORTC-QLQ C30 and LC13). The EORTC-QLQ C30 is the European Organization for Research and Treatment of Cancer Quality of Life Questionnaire, which consists of a set of validated 30 core questions assessing QOL in cancer patients, and the EORTC-QLQ LC13 is a modular supplement containing 13 questions specific to lung cancer patients [13]. Also, patients completed a two-minute walk test to measure cardiorespiratory endurance, a 30-second chair stand test to measure lower extremity muscle strength, a handgrip strength test to measure upper extremity muscle strength, and the International Physical Activity Questionnaire-Short Form(IPQ-SF) [14]. Based on these results, patients received exercise prescriptions and training from rehabilitation specialists and visited the rehabilitation department again in the $6^{\text {th }}$ and $12^{\text {th }}$ week of study to receive additional exercise training as well as re-assess exercise performance (Figure 3 ). The SAP satisfaction survey was conducted when patients visited the hospital in the $6^{\text {th }}$ and $12^{\text {th }}$ weeks of the study, and QOL questionnaires that were executed at the beginning and end of the study were compared to each other.

\section{Smart After-care Program (SAP)}

\subsection{Self-monitoring devices}

We provided self-monitoring devices to all subjects and installed a Smart After-care app on their smartphones. Self-monitoring devices included a Bluetooth electronic sphygmomanometer (UA-851PBTC, A\&D electronics Co., Ltd., Shen Zhen, China), finger pulse oximeter (Nonin Onyx Vantage 9590, MN, USA), and digital spirometer (PF-200, Micro life Corporation, Widnau, Switzerland). The choice of devices was made taking into consideration the characteristics of lung cancer patients, allowing for blood pressure, heart rate, oxygen saturation, and FEV1 (Forced Expiratory Volume within 1 second) to be obtained every morning. All participants were instructed to enter their daily vital signs into their smartphones. In addition, all participants were instructed to respond to a 13-question checklist on their subjective physical state adapted for the physical characteristics of lung cancer patients in the app (Supplementary Figure 1). If participants failed to input the information properly after waking up, the app was set to sound an alarm at 8 a.m. and 10 a.m., and if the patient (1) failed to input the information for three consecutive days, (2) had an oxygen saturation of less than 95 percent, (3) had heart rate above 120 beats/minute or below 50 beats/minute, (4) had a systolic blood pressure above $180 \mathrm{mmHg}$ or below $80 \mathrm{mmHg}$, (5) had a diastolic blood pressure above $110 \mathrm{mmHg}$, or (6) had an FEV1 that was reduced by 
more than $30 \%$ from their baseline, the counseling center was notified and called the patient (Supplementary Figure 2).

\subsection{Smart After-care application}

The Smart After-care app was made specifically for this study based, ran on the Android operating program, and included a personalized exercise program and diets for lung cancer patients in addition to recording vital signs. To encourage compliance with the prescribed exercise program, each movement was designed to be easy-to-follow using a video clip. The exercises consisted of muscle strength exercises using elastic bands, stretching exercises to increase flexibility, and breathing exercises to strengthen respiratory muscles. Maintaining good nutrition plays an important role in improving health as well as in the treatment of disease. Especially for cancer survivors, nutritional problems such as lack of appetite are frequent. To address these problems, in this study, the BMI of patients was calculated and classified as 6 grades according to the BMI classification criteria of the Korean Society of Obesity. Based on BMI grade, individual nutritional requirements were calculated using the Mifflin-St. Jeror formula [15]. And these individual nutritional requirements were divided into 8 groups, and 12 personalized diets were provided for each group through the app. Patients were able to check menu-specific nutrients, dietary calories, and special recipe videos at any time (Supplementary Figure 3).

\section{Survey information}

\subsection{SAP satisfaction survey}

The satisfaction survey consists of four main categories, as follows:

a. Overall satisfaction with the SAP and willingness to use it after this study (4 questions)

b. Opinions on the equipment and programs used in the SAP (6 questions)

c. Service usability assessment (7 questions)

d. Opinion on telephone health counseling by the counseling center (5 questions)

For each question, there were five response choices, as follows:

(1) Very good (Absolutely yes), (2) Good (Yes), (3) Fair (Average), (4) Poor (No), (5) Very poor (Absolutely no)

All the answers were standardized for statistical analysis. We investigated independent association between satisfaction level and relevant clinical factors through Kruskal-Wallis.

\subsection{Quality of life Survey}

The EORTC QLQ-30 consists of a functional scale and a symptom scale. The functional scale is divided into six categories, global health status (GHS), physical functioning (PF), role functioning (RF), emotional 
functioning (EF), cognitive functioning (CF), and social functioning (SF). The symptom scale consists of 8 symptoms, including nausea/vomiting, pain, dyspnea, insomnia, appetite, constipation, diarrhea. In addition, this study used the EORTC QLQ-LC13, developed as a QOL survey in lung cancer patients. The survey consists of 13 questions about cough, hemoptysis, dyspnea, sore mouth, dysphagia, peripheral neuropathy, alopecia, pain in the chest, pain in arm/shoulder, and other pain. Scores were calculated according to the EORTC QLQ-C30 version 3.0 scoring manual [16]. The QOL score changes for each area were compared through the Wilcoxon Signed-Rank Test (one-side, H1: Before < After).

\section{Statistical analysis}

Statistical analysis and processing of data was done using STATA 13. Continuous variables are represented by mean \pm standard deviations, and categorical variables are presented as median values. For continuous variables, the post-war comparison within the group was done using the Wilcoxon RankSum Test (one-side). A p-value of less than 0.05 was considered statistically significant.

\section{Results}

We conducted internal validation of the SAP satisfaction survey. Item internal consistency (IIC) was calculated to determine whether each of the four categories was well organized with consistency, and an item discriminant validity (IDV) $[17,18]$ was calculated to determine whether each of the categories were well separated from one another. The Cronbach's a value was 0.94 , showing very high survey reliability (Table 2).

In the final satisfaction survey, $88 \%$ of patients were "very good" or "good" in terms of overall satisfaction (Question 1). When we asked, 'Do you have any plans to use the SAP after this study?', 86\% of patients responded, "Absolutely yes" or "yes". In terms of convenience of using the equipment, $97.6 \%$ of patients answered, "very good" or "good" (Question 6). When we asked, "Did the SAP improve their trust in their medical care?", $97 \%$ of patients responded, "Absolutely yes" or "yes". When we asked, "Do you think the SAP is a good way to manage serious diseases?" (Question 17), 97\% of patients responded, "Absolutely yes" or "yes". Also, for overall satisfaction with telephone health counseling (Question 22), 76\% of patients responded, "very good" (Table 3).

The SAP satisfaction survey responses were standardized, and the lower the total score, the higher the satisfaction level. The correlation between satisfaction and age, gender, distance from hospital to residence, smoking history, lung cancer stage, comorbidity was investigated. As a result, only distance from the hospital to a patient's residence was found to be correlated with satisfaction level $(p=0.013)$ (Supplementary Table 1).

In the EORTC QLQ-C30 survey, for the functional scale, a significant improvement was observed in all subsections $(p<0.05)$. But no significant improvement was seen in the symptom scale. Similarly, no significant differences were observed in the EORTC QLQ-LC13 survey (Supplementary Table 2). 
There was no significant difference in upper extremity muscle strength, but significant improvements in lower extremity muscle strength were observed, with repetitions increasing from 18 to 22 for the 30second chair stand test $(p=0.012)$. Also, there was significant improvement in walking distance in the two-minute walk test $(185.7 \mathrm{~m} \rightarrow 195.0 \mathrm{~m} ; \mathrm{p}=0.028)$ (Supplementary Table 3).

\section{Discussion}

In this study, we found that the SAP can be useful in lung cancer patients. Subjects had a significant overall satisfaction with the SAP, and these results were reflected in their intentions for future use. Among the participants, five patients (10\%) dropped out because of the stress of adhering to the protocol of the SAP. However, $97 \%$ of those who completed the study were satisfied with the convenient use of the equipment. This suggests that patients were more adaptable to smartphones and electronic devices than expected. It may be explained with three reasons. First, patients with smartphones were selected for the study. Second, the average age of the patients in the study was 58 , indicating that relatively young patients participated in the study. Third, the research team collaborated extensively to manage patients. The counseling center provided a weekly telephone health counseling and re-trained patients in the use of the equipment at any time during the 12-week study period. Devices could be exchanged without delay, if necessary.

In lung cancer patients, aerobic exercise prevents postoperative complications and helps them recover quickly $[19,20]$. Furthermore, enhancing physical activity is related to increasing cancer survival and decreasing cancer recurrence rate [21]. Therefore, we emphasized personalized exercise and respiratory rehabilitation in this study. As a result, significant improvements in lower extremity muscle strength and two-minute walking distance were observed. As a cardiorespiratory endurance assessment for lung resection surgery, 6-minute walk test has been cited the most [22]. However, several previous studies have reported that a two-minute walk test may be safer and more useful for measuring cardiorespiratory endurance in the presence of impaired body function, such as in Parkinson's disease or in older adults [23]. We adopted a two-minute walk test considering the disease characteristics and lung function of the participants. There were no adverse events during the two-minute walk tests, and significant improvement was demonstrated by the test. Meanwhile, there was no significant change in upper extremity muscle strength. We believe that this was because upper body exercises were difficult to complete because of the pain in the chest wound area or limited shoulder joint movement of patients who experienced thoracic surgery. In the future, considering these characteristics of lung cancer surgery patients, it would be better to create a program focusing on strengthening flexibility rather than muscle strength.

After treatment for lung cancer, several survivors have poor QOL. Yun et al. analyzed the correlation between the QOL and mortality in patients with complete recovery after lung cancer surgery [24]. They found more severe the decreases in QOL had greater impacts on mortality and argued that there should be a systematic care program to evaluate and manage QOL which includes exercise and diet management, along with monitoring the recurrence of diseases after lung cancer treatment. From this perspective, the SAP can be an option. Conventionally, management of patient with lung cancer surgery 
involves only outpatient follow-up through chest CT every 3-6 months. We wanted to improve the QOL of the lung cancer patients more actively through this program and determine how the SAP helps improve QOL. Among the QOL indicators, all the functional scales improved significantly, which could have been the result of systematic management of SAP. However, symptom scales did not change significantly, presumably due to a relatively small proportion of patients who had surgery within 2 months of study initiation ( $n=12)$ or were undergoing chemotherapy $(n=4)$. In other words, it is believed that 26 patients $(62 \%)$ were enrolled in the study at a stage where acute symptoms had already recovered. In the future, if a randomized controlled study is conducted in patients with acute symptoms, the ability of the SAP to contribute to reducing symptoms can be determined more clearly.

Distance from hospital to residence was the only independent factor correlated with the satisfaction. For statistical analysis, we divided the distance into 3 categories (less than $20 \mathrm{~km}$, between $20 \mathrm{~km}$ and $80 \mathrm{~km}$, and more than $80 \mathrm{~km}$ ). The reason for this distinction is that if the distance is less than $20 \mathrm{~km}$, it can be classified as having good access to the hospital, and if it is more than $80 \mathrm{~km}$, it is very burdensome to go back and forth in a day. Satisfaction was significantly higher in patients whose residence was more than $80 \mathrm{~km}$ from the hospital $(p=0.013)$. Telemedicine like SAP does not involve in-person visits or examinations, but in fact, patients are able to communicate with the medical team more frequently than with conventional services. When a patient's condition is unstable, the SAP thought to be of greater help to take good first-aid measures and is expected to help reduce unnecessary hospital visits due to simple anxiety.

There are some study limitations. The number of participants was small as a pilot study and this study was designed for single arm. In the near future, a large-scale, prospective randomized controlled study will be needed to address this concern.

\section{Declarations}

\section{Acknowledgments}

The authors thank Seongjin Eo for the preparation of all documents.

\section{Data Availability}

The authors had full control of all of the primary data and will allow the journal to review the data if requested.

\section{Code availability}

N/A

\section{Funding}


The authors disclosed receipt of the following financial support for the research, authorship and/or publication of this article: This work was supported by the National Information Society Agency [grant number 1531180-1].

\section{Author information}

\section{Affiliations}

Center for Lung Cancer, Research Institute and Hospital, National Cancer Center, Goyang, Republic of Korea

Hee Chul Yang, Jin Ho Choi, Moon Soo Kim, Jong Mog Lee

Department of Rehabilitation Medicine, Research Institute and Hospital, National Cancer Center, Goyang, Republic of Korea

Seung Hyun Chung, Ji Sung Yoo

Biometric Research Branch, Research Institute and Hospital, National Cancer Center, Goyang, Republic of Korea

Boram Park

\section{Contributions}

All authors contributed to the study conception and design. The first draft of the manuscript was written by Hee Chul Yang. Material preparation, data collection, and analysis were performed by Boram Park and Hee Chul Yang. All authors commented on previous versions of the manuscript. All authors read and approved the final manuscript.

Corresponding author

Correspondence to Hee Chul Yang.

Ethics declarations

Conflict of interests

Authors declare no conflicts of interest.

\section{Ethis approval}

This study was approved by National Cancer Center Institutional Review Board (NCC2015-0205). 
Written informed consent was obtained from each participant prior to registration.

\section{Consent to publication}

All participants gave consent for publication.

\section{References}

1. Schneider MP, Gertsch A, Bugnon O (2013) Cyberhealth serving to support individual intake of medication. Swiss Med Wkly 143:w13827. https://doi.org/10.4414/smw.2013.13827

2. Glynn LG, Hayes PS, Casey M, Glynn F, Alvarez-Iglesias A, Newell J et al (2014) Effectiveness of a smartphone application to promote physical activity in primary care: the SMART MOVE randomised controlled trial. Br J Gen Pract 64(624):e384-e391. https://doi.org/10.3399/bjgp14X680461

3. Hirst JE, Mackillop L, Loerup L, Kevat DA, Bartlett K, Gibson 0 et al (2015) Acceptability and user satisfaction of a smartphone-based, interactive blood glucose management system in women with gestational diabetes mellitus. J Diabetes Sci Technol 9(1):111-115.

https://doi.org/10.1177/1932296814556506

4. Varnfield M, Karunanithi M, Lee CK, Honeyman E, Arnold D, Ding H et al (2014) Smartphone-based home care model improved use of cardiac rehabilitation in postmyocardial infarction patients: results from a randomised controlled trial. Heart 100(22):1770-1779. https://doi.org/10.1136/heartjnl-2014-305783

5. Patel MSAD, Volpp KG (2015) Wearable devices as facilitators, not drivers, of health behavior change. JAMA 313(5):459-460. https://doi.org/10.1001/jama.2014.14781

6. Silverman RD (2003) Current legal and ethical concerns in telemedicine and e-medicine. J Telemed Telecare 9 Suppl 1:S67-S69. https://doi.org/10.1258/135763303322196402

7. Chung YS, Kim Y, Lee CH (2014) Effectiveness of the smart care service for diabetes management. Healthc Inform Res 20(4):288-294. https://doi.org/10.4258/hir.2014.20.4.288

8. Kim HS, Choi W, Baek EK, Kim YA, Yang SJ, Choi IY et al (2014) Efficacy of the smartphone-based glucose management application stratified by user satisfaction. Diabetes Metab J 38(3):204-210. https://doi.org/10.4093/dmj.2014.38.3.204

9. Kim YJRS, Byun JK et al (2015) A Smartphone Application Significantly Improved Diabetes Self-Care Activities with High User Satisfaction. Diabetes Metab J 39(3):207-217. https://doi.org/10.4093/dmj.2015.39.3.207

10. Kumar N, Khunger M, Gupta A, Garg N (2015) A content analysis of smartphone-based applications for hypertension management. J Am Soc Hypertens 9(2):130-136. https://doi.org/10.1016/j.jash.2014.12.001

11. Oresko JJ, Duschl H, Cheng AC (2010) A wearable smartphone-based platform for real-time cardiovascular disease detection via electrocardiogram processing. IEEE Trans Inf Technol Biomed 14(3):734-740. https://doi.org/10.1109/TITB.2010.2047865 
12. Jemal A, Siegel R, Ward E, Hao Y, Xu J, Murray T et al (2008) Cancer statistics, 2008. CA Cancer J Clin 58(2):71-96. https://doi.org/10.3322/CA.2007.0010

13. Bergman B, Aaronson NK, Ahmedzai S, Kaasa S, Sullivan M (1994) The EORTC QLQ-LC13: a modular supplement to the EORTC Core Quality of Life Questionnaire (QLQ-C30) for use in lung cancer clinical trials. EORTC Study Group on Quality of Life. Eur J Cancer 30A(5):635-642. https://doi.org/10.1016/0959-8049(94)90535-5

14. Lee PH, Macfarlane DJ, Lam TH, Stewart SM (2011) Validity of the International Physical Activity Questionnaire Short Form (IPAQ-SF): a systematic review. Int J Behav Nutr Phys Act 8:115. https://doi.org/10.1186/1479-5868-8-115

15. Mifflin MD, St Jeor ST, Hill LA, Scott BJ, Daugherty SA, Koh YO (1990) A new predictive equation for resting energy expenditure in healthy individuals. Am J Clin Nutr 51(2):241-247. https://doi.org/10.1093/ajcn/51.2.241

16. Fayers PMAN, Bjordal K et al (2001) EORTC QLQ-C30 scoring manual

17. Lee Y, Lim MC, Son Y, Joo J, Park K, Kim JS et al (2014) Development and evaluation of Korean version of Quality of Sexual Function (QSF-K) in healthy Korean women. J Korean Med Sci 29(6):758-763. https://doi.org/10.3346/jkms.2014.29.6.758

18. Lim MC, Lee JS, Joo J, Park K, Yoo HJ, Seo SS et al (2014) Development and evaluation of the Korean version of the Gynecologic Cancer Lymphedema Questionnaire in gynecologic cancer survivors. Gynecol Oncol 133(1):111-116. https://doi.org/10.1016/j.ygyno.2014.01.040

19. Benzo RWD, Novotny $P$ et al (2011) Preoperative pulmonary rehabilitation before lung cancer resection: results from two randomized studies. Lung Cancer 74(3):441-445. https://doi.org/10.1016/j.lungcan.2011.05.011

20. Cesario A, Dall'Armi V, Cusumano G, Ferri L, Margaritora S, Cardaci V et al (2009) Post-operative pulmonary rehabilitation after lung resection for NSCLC: a follow up study. Lung Cancer 66(2):268269. https://doi.org/10.1016/j.lungcan.2009.08.002

21. Jones LW, Eves ND, Waner E, Joy AA (2009) Exercise therapy across the lung cancer continuum. Curr Oncol Rep 11(4):255-262. https://doi.org/10.1007/s11912-009-0036-0

22. Arbane G, Tropman D, Jackson D, Garrod R (2011) Evaluation of an early exercise intervention after thoracotomy for non-small cell lung cancer (NSCLC), effects on quality of life, muscle strength and exercise tolerance: randomised controlled trial. Lung Cancer 71(2):229-234.

https://doi.org/10.1016/j.lungcan.2010.04.025

23. Leung AS, Chan KK, Sykes K, Chan KS (2006) Reliability, validity, and responsiveness of a 2-min walk test to assess exercise capacity of COPD patients. Chest 130(1):119-125. https://doi.org/10.1378/chest.130.1.119

24. Yun YH, Kim YA, Sim JA, Shin AS, Chang YJ, Lee J et al (2016) Prognostic value of quality of life score in disease-free survivors of surgically-treated lung cancer. BMC Cancer 16:505. https://doi.org/10.1186/s12885-016-2504-x 


\section{Tables}

Page 12/18 
Table 1

Patient characteristics

\begin{tabular}{|c|c|}
\hline Variable & Smart After-care $(n=50)$ \\
\hline Basic personal information & $58.0 \pm 11.9$ \\
\hline \multicolumn{2}{|l|}{ Age (Mean \pm SD) } \\
\hline Gender (M:F) & $28: 22$ \\
\hline $\mathrm{BMI}\left(\mathrm{kg} / \mathrm{m}^{2}\right)$ & $23.4 \pm 2.8$ \\
\hline \multicolumn{2}{|l|}{ Comorbidities } \\
\hline Hypertension & 9 \\
\hline Diabetes & 5 \\
\hline \multicolumn{2}{|l|}{ Smoking status } \\
\hline Current & 17 \\
\hline Never & 26 \\
\hline Ex-smoker & 7 \\
\hline \multirow{2}{*}{\multicolumn{2}{|c|}{$\begin{array}{l}\text { Lung Cancer Stage } \\
\text { (AJCC 8th edition) }\end{array}$}} \\
\hline & \\
\hline$\square \mathrm{A}$ & 19 \\
\hline$\varangle \mathrm{B}$ & 8 \\
\hline$\bigotimes \mathrm{A}$ & 3 \\
\hline$\bigotimes \mathrm{B}$ & 3 \\
\hline$\bigotimes \mathrm{A}$ & 12 \\
\hline$\llbracket \mathrm{B}$ & 0 \\
\hline 口 & 5 \\
\hline \multicolumn{2}{|l|}{ Treatment } \\
\hline Lobectomy & 35 \\
\hline Wedge resection & 8 \\
\hline Pneumonectomy & 1 \\
\hline Segmentectomy & 2 \\
\hline
\end{tabular}

SD: Standard Deviation, BMI: Body Mass Index, RT: Radiotherapy. 


\begin{tabular}{|ll|}
\hline Variable & Smart After-care $(\mathbf{n = 5 0 )}$ \\
\hline Chemotherapy \pm RT & 4 \\
(No surgery) & \\
\hline SD: Standard Deviation, BMI: Body Mass Index, RT: Radiotherapy. \\
\hline
\end{tabular}

Table 2

The characteristics and internal validation of Smart After-care Program satisfaction questionnaire: Each domain consists of satisfaction questionnaire items related the subject. The higher IIC and IDV values indicate better domain classification of the questionnaire.

\begin{tabular}{|c|c|c|c|c|c|c|c|}
\hline & $\begin{array}{l}\text { No. of } \\
\text { items }\end{array}$ & $\begin{array}{l}\text { IIC } \\
\text { (min- max) }\end{array}$ & $\begin{array}{l}\text { IDV } \\
\text { (min - max) }\end{array}$ & $\begin{array}{l}\text { IDV } \\
(\%)\end{array}$ & $\begin{array}{l}\text { Median scale } \\
\text { score }\end{array}$ & \multicolumn{2}{|c|}{$\begin{array}{l}\text { Cronbach's a } \\
(\mathrm{N}=42)\end{array}$} \\
\hline Domain $1^{\mathrm{a}}$ & 4 & $0.60-0.79$ & $0.22-0.74$ & 100 & $15(10,20)$ & 0.88 & 0.94 \\
\hline Domain $2^{b}$ & 6 & $0.51-0.82$ & $0.23-0.67$ & 83.3 & $11.7(10,16.7)$ & 0.85 & \\
\hline Domain $3^{c}$ & 7 & $0.39-0.67$ & $0.22-0.69$ & 80.9 & $13.6(10,18.6)$ & 0.85 & \\
\hline Domain $4^{d}$ & 5 & $0.67-0.90$ & $0.34-0.82$ & 93.3 & $10(10,15.5)$ & 0.91 & \\
\hline
\end{tabular}

Table 3. Satisfaction level for Smart After-care Program: A total of 22 questions were recorded with no missing responses and scales were quantified for statistical analysis. Very good (Absolutely yes) $=1$, Good (Yes) =2, Fair (Average) =3, Poor (No) =4, Very poor (Absolutely no) $=5$ 


\begin{tabular}{|c|c|c|c|c|c|c|c|}
\hline $\begin{array}{l}\text { Question } \\
\text { number }\end{array}$ & Mean & SD & $\begin{array}{l}\text { Very } \\
\text { good }\end{array}$ & $\begin{array}{l}\text { Good } \\
\text { (yes) }\end{array}$ & $\begin{array}{l}\text { Fair } \\
\text { (average) }\end{array}$ & $\begin{array}{l}\text { Poor } \\
\text { (no) }\end{array}$ & $\begin{array}{l}\text { Very } \\
\text { poor }\end{array}$ \\
\hline & & & $\begin{array}{l}\text { (Absolutely } \\
\text { yes) }\end{array}$ & & & & $\begin{array}{l}\text { (Absolutely } \\
\text { no) }\end{array}$ \\
\hline
\end{tabular}

\section{Satisfaction}

\begin{tabular}{llllllll}
1 & 1.5 & 0.70 & 26 & 11 & 5 & 0 & 0 \\
\hline 2 & 1.5 & 0.70 & 26 & 11 & 5 & 0 & 0 \\
\hline 3 & 1.71 & 0.70 & 18 & 18 & 6 & 0 & 0 \\
\hline 4 & 1.78 & 0.81 & 18 & 16 & 7 & 1 & 0
\end{tabular}

\section{Ease of use}

\begin{tabular}{llllllll}
5 & 1.54 & 0.73 & 24 & 14 & 3 & 1 & 0 \\
\hline 6 & 1.28 & 0.50 & 31 & 10 & 1 & 0 & 0 \\
\hline 7 & 1.26 & 0.49 & 32 & 9 & 1 & 0 & 0 \\
\hline 8 & 1.35 & 0.65 & 30 & 10 & 1 & 1 & 0 \\
\hline 9 & 1.30 & 0.46 & 29 & 13 & 0 & 0 & 0 \\
\hline 10 & 1.45 & 0.59 & 25 & 15 & 2 & 0 & 0
\end{tabular}

\section{Service} usefulness

\begin{tabular}{llllllll}
11 & 1.52 & 0.70 & 24 & 15 & 2 & 1 & 0 \\
\hline 12 & 1.47 & 0.59 & 24 & 16 & 2 & 0 & 0 \\
\hline 13 & 1.45 & 0.59 & 25 & 15 & 2 & 0 & 0 \\
\hline 14 & 1.61 & 0.69 & 20 & 19 & 2 & 1 & 0 \\
\hline 15 & 1.40 & 0.54 & 26 & 15 & 1 & 0 & 0 \\
\hline 16 & 1.38 & 0.53 & 27 & 14 & 1 & 0 & 0 \\
\hline 17 & 1.28 & 0.50 & 31 & 10 & 1 & 0 & 0
\end{tabular}

\section{Telephone counseling}

\begin{tabular}{llllllll}
18 & 1.33 & 0.57 & 30 & 10 & 2 & 0 & 0 \\
\hline 19 & 1.11 & 0.32 & 37 & 5 & 0 & 0 & 0 \\
\hline 20 & 1.30 & 0.46 & 29 & 13 & 0 & 0 & 0 \\
\hline 21 & 1.35 & 0.53 & 28 & 13 & 1 & 0 & 0 \\
\hline
\end{tabular}




\section{Figures}

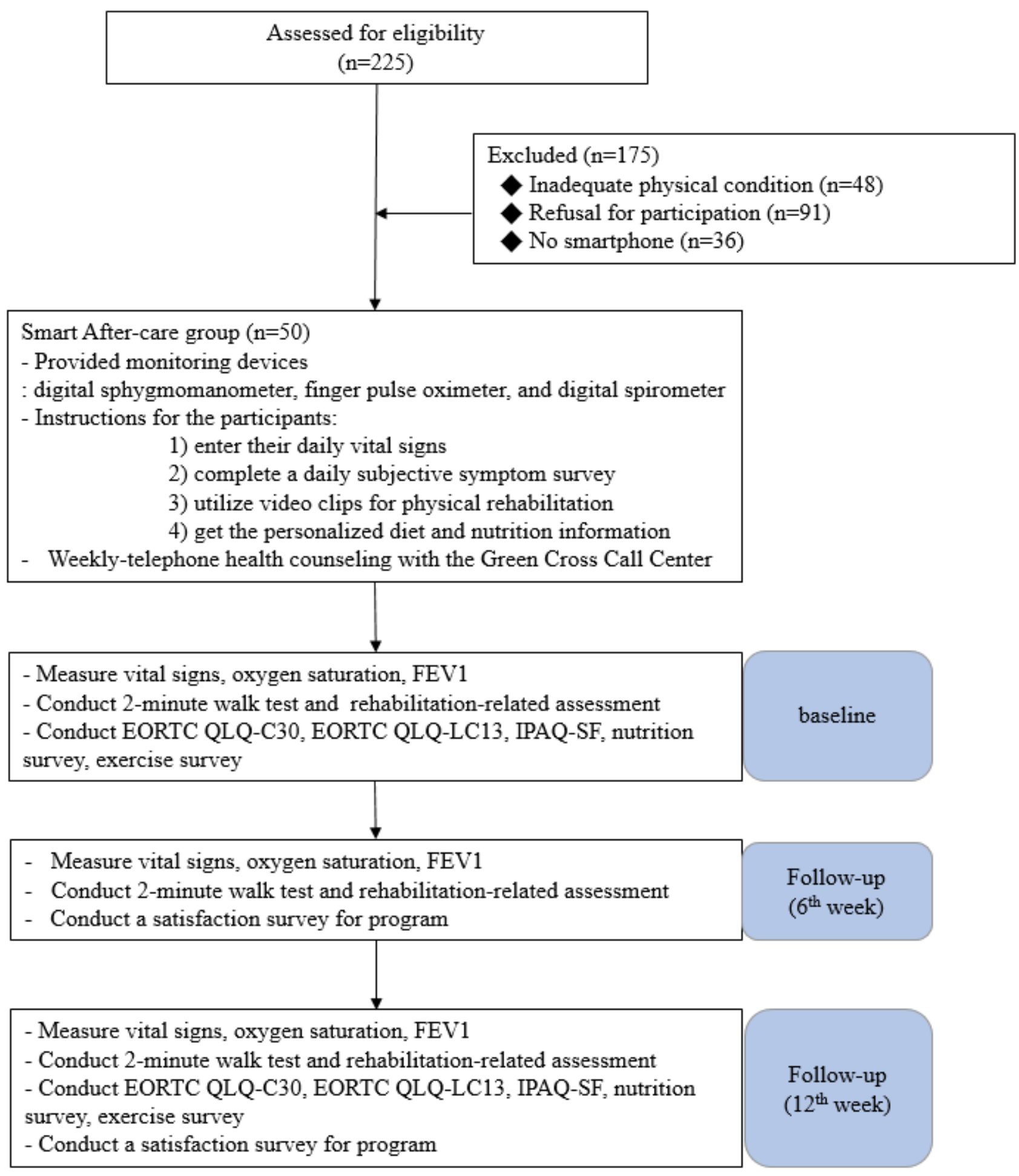

\section{Figure 1}

Flow diagram and overview of timeline 


\section{Interval between lung resection surgery and study enrollment}

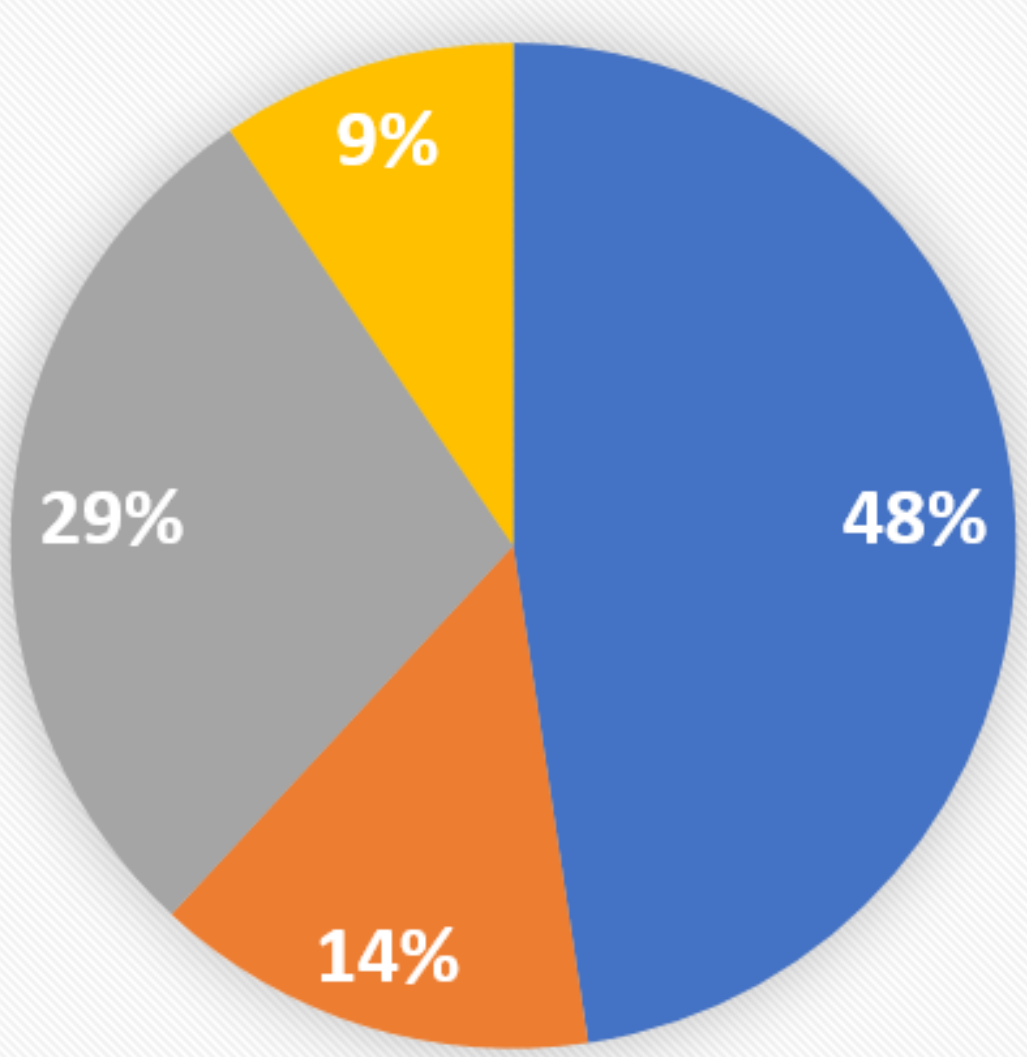

more than 1 year after surgery $(n=20)$ less than 1 year after surgery $(n=6)$

n less than 2 month after surgery $(n=12)$ " only chemotheraphy $(n=4)$

\section{Figure 2}

Interval between lung resection surgery and study enrollment 
A

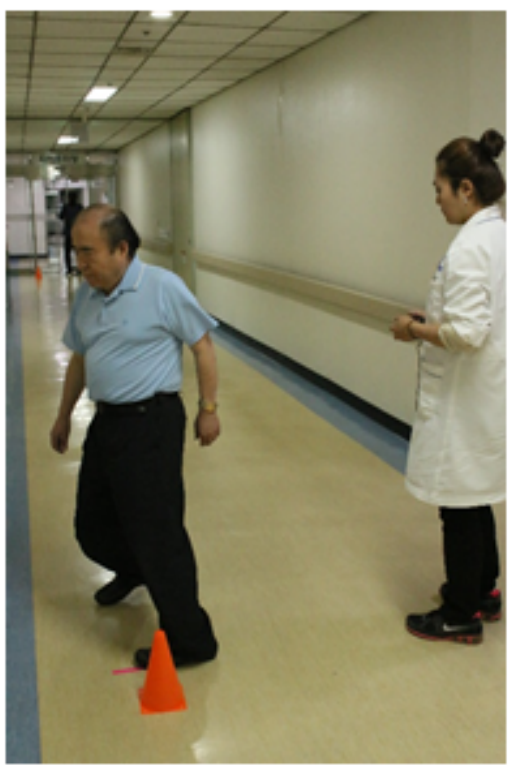

B

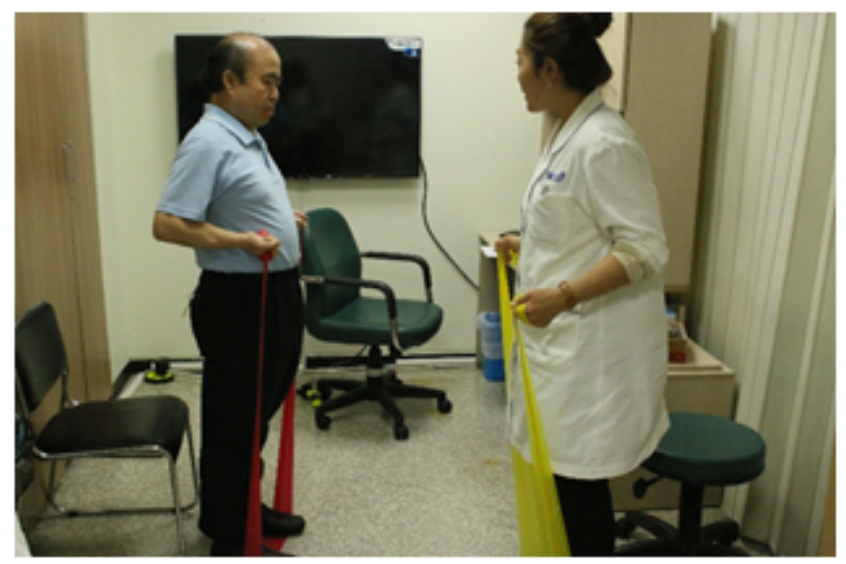

Figure 3

(A) 2-minute walk test; The distance walked in 2 minutes was recorded. (B) Muscle exercise training using elastic band.

\section{Supplementary Files}

This is a list of supplementary files associated with this preprint. Click to download.

- SupplementaryFigureSAPSCiCDr.Yang.rtf

- SupplementaryTableSAPSCiCDr.Yang.docx 